\title{
Primary Mediastinal Cysts: A Review of 41 Surgically Managed Cases
}

\author{
E Akar ${ }^{1}, \mathrm{~T}$ Erkinüresin ${ }^{2}$
}

\begin{abstract}
Objective: In this study we aimed to review the surgical outcomes of primary mediastinal cysts and to determine the differences among various histopathological types.

Methods: We retrospectively analyzed the medical records of 41 patients (19 men, 22 women; mean age $46.5 \pm 13.7$ years, range 19-78 years) with primary mediastinal cysts who underwent surgical excision betweeen January 2007 and January 2016. Age, sex, indication for surgical intervention, surgical technique, histopathological diagnosis, postoperative complications, and duration of hospital stay were recorded for all patients. The differences among the various histological types of primary mediastinal cysts were determined using analysis of variance (ANOVA) for continuous variables and Chi-square test for categoric variables. A p value of less than 0.05 was considered statistically significant.
\end{abstract}

Results: A total of 41 patients with primary mediastinal cysts were managed surgically at our clinic over a period of 9 years. A total of 19 men (46.3\%) and 22 women (53.7\%) were included in the study. The patients had a mean age of $46.5 \pm 13.7$ years, a mean duration of hospital stay of $4.0 \pm 1.0$ days, and a mean postoperative follw-up duration of $11.2 \pm 3.7$ months. According to the histopathological analysis, $21(51.2 \%)$ patients were diagnosed as having a pericardial cyst; 16 (39\%) had a bronchogenic cyst; 3 (7.3\%) had a cystic hygroma; and $1(2.4 \%)$ had a thymic cyst. No postoperative mortality or recurrence was observed over a period of $11.2 \pm 3.7$ months. No statistically significant difference was found among the variables, either.

Conclusion: Despite advanced non-invasive diagnostic techniques, the definitive diagnosis of primary mediastinal cysts can only be made by interventional techniques. Surgery often provides curative therapy with low morbidity and mortality.

Keywords: Bronchogenic cyst, cyst, mediastinum, thoracotomy

From: ${ }^{1}$ Department of Thoracic Surgery Clinic, Bursa Yuksek Ihtisas Training and Research Hospital and ${ }^{2}$ Department of Pathology Clinic, Bursa Yuksek Ihtisas Training and Research Hospital, Bursa, Turkey.

Correspondence: Dr E Akar, Department of Thoracic Surgery Clinic, Bursa Yuksek Ihtisas Training and Research Hospital, Bursa, Turkey. Fax: +902242955497, e-mail: drerkanakar@hotmail.com 


\section{INTRODUCTION}

Mediastinal masses may originate from any thoracic organ and display a wide array of pathological findings as malignant and benign lesions (1). Primary mediastinal masses (PMM) constitute approximately $10-25 \%$ of these masses $(1,2)$. These PMM lesions are congenital or acquired, or formed as a result of the degeneration of a previously existing solid tumor (1). Therefore, cystic lesions may occur in both childhood and adulthood. Primary mediastinal cysts (PMC) may display a wide array of histological types, such as thymic cysts (TC), bronchogenic cysts (BC), pericardial cysts (PC), and lymphangiomas (cystic hygroma). Although symptomatic PMCs are unequivocally considered an indication for surgery, the management of asymptomatic PMCs is still contraversial. Some surgeons prefer surgical management due to a fear of malignant transformation, cyst infection, progressive growth, or spontaneous rupture, while some others advocate that not all PMCs should be removed given the benign nature of these lesions (3-5). Despite this uncertainty, literature data on the surgical experience in PMCs is considerably limited.

The aim of this study was to review the outcomes of the surgical procedures aimed at treating PMCs at our institution in the last 9 years and to report the clinicopathological variations with a discussion of the relevant literature.

\section{SUBJECTS AND METHODS}

We reviewed the medical data of 41 patients (19 men, 22 women; mean age $46.5 \pm 13.7$ years (range 19-78 years)) diagnosed with PMC by the histological examination after surgical treatment between January 2007 and January 2016. Patients who were not treated surgically but followed conservatively were excluded. The examined variables included age, sex, indication for surgical treatment, side of surgical treatment, histopathological diagnosis, time 
to chest tube removal, duration of hospital stay, and postoperative complications. The study protocol was approved by the local ethics comittee of our hospital. The study was conducted in compliance with the criteria of the Helsinki Decleration.

In the preoperative period, a posteroanterior chest film, thoracic computed tomography (CT) examination with contrast enhancement, and/or pulmonary mediastinal magnetic resonance imaging (MRI) taken within the preceding month were reviewed by the surgeon operating on the patients. All patients underwent complete blood count, routine biochemistry tests, respiratory function testing, and cardiological examination with electrocardiography as well as echocardiographic examination as needed. All patients were informed about the advantages and disadvantages of the thoracotomy, sternotomy, and video-assisted thoracoscopic surgery (VATS) approaches.

\section{Operative technique}

All patients were intubated with a double-lumen endotracheal tube following general anesthesia, except for one patient who was operated on with median sternotomy. Patients to be operated on with thoracotomy were placed in right or left posterolateral thoracotomy position depending on the lesion's side, and the thoracic cavity was entered through the fifth intercostal space. The thoracoscopic operations were performed using 3-4 ports with the patients lying in the lateral position. In the thymic cyst case, the patient was placed in the supine position following single lumen intubation. A pillow support was placed in the interscapular area, and median sternotomy was performed (due to our inexperience in endoscopy). Total excision was carried out and extubation was performed at the operating theatre in all patients. All patients had a control chest X-Ray at the early postoperative period.

\section{Statistical analysis}

The differences between various histological types of PMC were compared with the analysis of variance (ANOVA) test for continuous variables and Chi-square test for categoric 
variables. A p value of less than 0.05 was considered significant for all tests. All statistical analyses were carried out using SPSS version 21.0 (IBM) software package.

\section{RESULTS}

A total of 41 patients with PMC were surgically tretaed over a period of 9 years. As a total, 19 (46.3\%) men and 22 (53.7\%) women were enrolled. The age range of the study subjects was $46.5 \pm 13.7$ years; the postoperative duration of hospital stay was $4.0 \pm 1.0$ days; and the postoperative duration of follow-up was $11.2 \pm 3.7$ months. Based on the histopathological examination, $21(51.2 \%)$ patients were diagnosed as having a pericardial cyst, $16(39 \%)$ had a bronchogenic cyst, $3(7.3 \%)$ had a cystic hygroma, and $1(2.4 \%)$ had a thymic cyst. The operations were right-sided in $22(53.7 \%)$ patients, left-sided in $18(43.9 \%)$ patients, and in supine poisiton in $1(2.4 \%)$ patient. No postoperative mortality was observed, nor there was any recurrence after a mean of $11.2 \pm 3.7$ months. Table 1 provides a comparison of cinical characteristics, treatment modalities, and follow-up information of 41 patients. No significant difference was found between the groups with respect to studied variables (sex, age, pathological diagnosis).

\section{Bronchogenic cyst}

Eight of 16 bronchogenic cyst cases were asymptomatic. Six patients had cough and 2 had dyspnea. In thoracic CT and MRI examinations, 2 patients had lesions in anterior mediastinum, 9 had lesions in middle mediastinum, and 5 had lesions in posterior mediastinum. Thirteen patients were operated on with thoracotomy and 3 with the VATS technique. One patient had atelectasis and another one had prolonged air leakage as a postoperative complication. 


\section{Pericardial cyst}

While 15 of 21 patients with pericardial cyst were asymptomatic, 6 had chest pain, cough, and dyspnea. All lesions were located in middle mediastinum. Seventeen patients were operated on with thoracotomy and 4 with VATS. As a postoperative complication, 2 patients developed atelectasis, 1 wound site infection, and 1 transient phrenic nerve paralysis.

\section{Cystic hygroma}

Of 3 patients with cystic hygroma, 2 were asymptomatic while 1 patient had chest pain and dyspnea. The lesions were in middle mediastinum. After showing the relationship of the $\mathrm{CH}$ with the adjacent tissues, all 3 patients were operated on with thoracotomy. The cyst was filled with a serous fluid and enveloped by a thin, transparent membrane. One patient developed minimal postoperative hemorrhage.

\section{Thymic cyst}

The patient with the thymic cyst had chest pain and dyspnea. The lesion was located in anterior mediastinum. On thoracic CT, there was a thin-walled cyst filled with a cystic content of fluid density. Lung MRI was used to reveal the borders of the cyst with other adjacent organs. It was observed to have a low signal intensity on T1 weighted images and a high signal intensity on $\mathrm{T} 2$ weighted images. We totally excised the thymic cyst with median sternotomy.

\section{DíSCUSSİON}

PMC lesions appear as congenital or acquired lesions, or as a result of the degeneration of a previously existing solid tumor. The prevalence of PMCs among mediastinal masses ranges between $10 \%$ and $25 \%$. They affect both sexes equally (6). 
The prevalence of cysts varies by age groups. While foregut cysts constitute approximately half of congenital mediastinal cysts in adults, $90 \%$ of all cysts are foregut cysts (BC, enteric cyst, neuroentec cyst) in the pediatric age group. PC is more common among adults whereas its extremely rare in the pediatric age group $(1,2,6)$. Depending on cyst size and adjacent organ compression, patients may present with variable symptoms and clinical presentations.

Asymptomatic congenital cysts may not be detected until adulthood. BCs (mediastinal-bronchogenic) typically arise along the tracheobronchial tree. They are wellcircumscribed cystic lesions of bronchopulmonary origin typically located in the middle mediastinum. They constitute approximately half of all mediastinal cysts (7). In a study comprising 86 patients under follow-up for mediastinal and lung BCs, $72.1 \%$ of all patients were symptomatic. In the same study, $67 \%$ of patients with mediastinal BC were symptomatic, as were $90 \%$ of patients having lung $\mathrm{BC}(8)$.

The most common symptom of patients with $\mathrm{BC}$ was retrosternal pain $(61.4 \%)$ while those with lung BC mostly had cough, dyspnea, fever, and purulent sputum (8). In a domestic case series containing 22 patients from all age groups, $81 \%$ of patients were symptomatic, with cough being the most common symptom (45\%) (9). Although BC has been reported as the most common histological variant of PMC, PC was the most common variant in our series, which was responsible for almost half of cases $(n=21 ; 51.2 \%)(3,4)$. Eight of our BC cases $(n=16)$ were asymptomatic. Six patients had cough and 2 had dyspnea. The cysts were located in anterior mediastinum in 2 patients, middle mediastinum in 9, and posterior mediastinum in 5 . Signs of BC can be found on plain films in $2 / 3$ of patients. It is typically seen as a well-circumscribed, round, homogenous mass lesion of 2-10 $\mathrm{cm}$ in diameter. When a cyst opens into a bronchus or is infected, however, an air-fluid level may become evident (1). 
Thoracic CT is the most commonly employed diagnostic method in the evaluation of BCs, mainyl due to its ability to provide a detailed information about a cyst's structure, density, properties of its fluid, calcium content of its wall, its relationship with neighbouring structures, and its vascular supply $(1,9)$. MRI provides information depending on a cyst's content. In cysts with fluid content, very low density images are obtained on T1-weighted sections and very high density images on T2-weighted sections. However, due to low-quality images, it is rarely used in cysts containing a large amount of proteinaceous material (9). Moreover, thoracic CT is superior to MRI for the evaluation of an intraparenchymal BCs since it may more clearly distinguish a cyst from an aerated region (1). Thoracic CT was also the most commonly used diagnostic method in our series $(n=13)$.

There are some case reports on the use of more invasive histopathological diagnostic methods such as bronchoscopy, endobronchial and esophageal ultrasonography (EBUS and EUS), mediastinoscopy, and thoracoscopy, for the diagnosis of BC (10). Surgical resection is the single method used for confirming the diagnosis (9). If patients are not treated surgically, most of them develop symptoms and complications. Moreover, it has been reported that some patients who are left untreated may develop malignancy originating from cyst mucosa $(1,9$, 11). It is particularly recommended that all symptomatic patients be treated surgically $(1,8,9$, 12). Therefore, thoracotomy is usually needed fot resection $(1,8,12)$. It has been reported that lobectomy is the best surgical choice for intraparenchymal BCs and wedge resection for peripherally located small cysts (13). Mediastinal BCs can also be treated using mediastinoscopy through a small incision $(1,14)$. It has been reported that VATS can achieve favourable results in the resection of mediastinal cysts, with recurrence rates being not increased $(15,16)$. Some recent studies have indicated that robotic surgery can be safely used with low morbidity for the treatment of mediastinal tumors and cysts $(17,18)$. As we were in 
the beginning of the VATS experience, we performed VATS for 3 patients and thoracotomy for the remaining 13 patients.

$\mathrm{PC}$ is a benign pathological lesion developing as a result of incomplete lacunar fusion during the formation of coelomic cavity during the intrauterine period (19). It is extremely rare in the childhood period (1). Its incidence is $1 / 100.000$ and constitutes $7 \%$ of all mediastinal mass lesions (19). Cyst wall is lined by a single layer of mesothelial cells and connective tissue that is rich in elastic and collagen fibers. A cysts' size varies between 1 and $30 \mathrm{~cm}(19,20)$. Cysts can be found in any mediastinal compartment from upper mediastinum to diaphragma (21). They are most commonly located in the lateral basal corner of the pericardium where it meets diaphragma (cardiophrenic angle), and mostly in the right cardiophrenic angle $(51-70 \%)(1,22)$.

$\mathrm{PC}$ is usually adymptomatic $(1,19,23)$. It may rarely give rise to compressive signs (right ventricular outflow obstruction, pulmonary stenosis secondary to compression, cyst rupture, and sudden death) (23). In our patients with PC, the lesions were located in middle mediastinum; while 15 patients were asymptomatic, 6 had chest pain, cough, and dyspnea. The cyst appears as a well-circumscribed, round or oval mass in the costophrenic angle on conventional chest films (1). Used for definitive diagnosis, thoracic CT attains a diagnostic accuracy of nearly $100 \%$. Thoracic CT and MRI have no superiority over each other. In our series, the radiological diagnosis of PC was made by thoracic CT in 15 patients and MRI in 6 patients. PCs are benign lesions for which there exists no clear consensus for therapy. Surgery is usually recommended when radiological cyst size changes or when certain signs such as arrhythmia, hemodynamic instability, pericarditis, or tamponade emerge $(1,19,20,22,23)$.

However, malignant transformation has been described in the literature; therefore, surgery is recommended even for asymptomatic cases. A choice between an endoscopic and 
open surgical approach is influenced by cyst's location, size, and relationship with vital organs $(1)$.

$\mathrm{CH}$ is a multilocular, thin-walled cystic mass of lymphatic origin. Approximately $1 \%$ of all lymphangiomas are located in the mediastinum. It is a rare tumor that usually develops in the first decade of life. The major reason of its rare occurrence is its asymptomatic nature or very delayed symptoms. Its etiology commonly involves abnormal dilatation of the lymphatic system (24). Although typically located in anterior mediastinum, it may also be seen in middle mediastinum. Although ultrasonography and thoracic CT are quite helpful for making the diagnosis by detecting $\mathrm{CH}$, definitive diagnosis is made by histopathological examination. On ultrasonography it appears as having septae composed of multilocular masses with a dominant cystic appearance.

Thoracic $\mathrm{CT}$ and MRI delineate the relationship of $\mathrm{CH}$ with the surrounding structures (25). In one of our cases in which mediastinal $\mathrm{CH}$ was found, an MRI was taken to clarify the relationship of the lesion with great vessels. Although some authors have recommended a conservative therapy for asymptomatic $\mathrm{CH}$ cases, spontaneous regression of these lesions is rare (25). A number of authors have reported favourable outcomes with total surgical excision (25). Riechelmann et al (24) did not observe any recurrence after total excision but did so in $56 \%$ of cases after subtotal excision and $100 \%$ of cases after partial excision or aspiration. We carried out total excision for all of our patients and observed no recurrences after a mean follow-up period of $11.2 \pm 3.7$ months.

$\mathrm{TC}$ is a rare lesion located in anterior mediastinum, which may be both congenital and acquired $(1,6)$. It is believed that congenital cysts develop from remnants of the bronchial sac. Acquired ones are seen after infections, trauma, or immune pathologies. It constitutes less than $1 \%$ of mediastinal lesions (26). 
Symptoms depend on a cyst's localization and relationship with adjacent organs (26). Despite being a benign lesion, it should be differentiated from malignant tumors of anterior mediastinum (such as thymoma, germ cell tumors, and lymphoma) (1). It appears as a wellcircumscribed mass lesion in anterior and superior mediastinum. The typical sign on thoracic CT is a thin-walled cyst and cyst content of fluid density. Lung MRI clearly demonstrates the relationship of a cyst with adjacent organs (1). Surgical intervention via thoracotomy or thoracoscopy are recommended both for making differential diagnosis and providing a curative therapy $(1,6,26)$.

\section{CONCLUSION}

Despite advanced noninvasive diagnostic methods, definitive diagnosis of PMC lesions can usually only be achieved by surgical interventions. Surgery is usually a curative option with low morbidity and mortality.

\section{AUTHORS' NOTE}

E Akar conceived paper, oversaw data collection, conducted data analysis, statistical analysis, wrote manuscript and approved final version. T Erkinüresin participated in study design, data analysis and interpretation, critically revised manuscript and approved final version. The authors declare that they have no conflicts of interest. The authors declare that they received no financial funding support for the conduction of their study project and writing of this manuscript. 


\section{REFERENCES}

1. Sodha NR, DeCamp MM. Congenital cysts of the mediastinum: bronchopulmonary foregut anomalies. In: Fishman AP, Elias JA, Fishman JA, Grippi MA, Senior RM, Pack Al, eds. Fishman's Pulmonary Diseases and Disorders. 4th ed. New York: Mc Graw-Hill;2008:p.1571-81.

2. Takeda S, Miyoshi S, Minami M, Ohta M, Masaoka A, Matsuda H, et al. Clinical spectrum of mediastinal cysts. Chest 2003; 124:125-32.

3. Esme H, Eren S, Sezer M, Solak O. Primary mediastinal cysts: clinical evaluation and surgical results of 32 cases. Tex Heart Inst J 2011; 38: 371-4.

4. Zambudio AR, Lanzas JT, Calvo MJ, Fernandez PJ, Paricio PP. Nonneoplastic mediastinal cysts. Eur J Cardiothorac Surg 2002; 22: 712-6.

5. Yoshiki Kozu, Kenji Suzuki, Shiaki Oh, Takeshi Matsunaga, Yukio Tsushima, Kazuya Takamochi. Single Institutional Experience with Primary Mediastinal Cysts: Clinicopathological Study of 108 Resected Cases. Ann Thorac Cardiovasc Surg 2014; 20: $365-9$

6. Strollo DC, Rosado-De-Christenson ML. Disorders of mediastinum. In: Albert RK, Spiro SG, Jett JR, eds. Clinical Respiratory Medicine. 3rd ed. Philadelphia: Mosby Elsevier. 2008;p.633-45.

7. Işıtmangil T, Balkanlı K. Mediastinal Kistler. In: Ökten İ, Güngör A, editörler. Göğüs Cerrahisi Cilt II. Ankara: Sim Matbaacıl1k 2003;s.1153-1171.

8. St-Georges R, Deslauriers J, Duranceau A, Vaillancourt R, Deschamps C, Beauchamp $\mathrm{G}$, et al. Clinical spectrum of bronchogenic cysts of mediastinum and lung in the adult. Ann Thorac Surg 1991; 52: 6-13.

9. Liu HS, Li SQ, Cao ZL, Zhang ZY, Ren H. Clinical features and treatment of bronchogenic cysts in adults. Chin Med Sci J 2009; 24: 60-3. 
10. Casal RF, Jimenez CA, Mehran RJ, Eapen GA, Ost D, Sarkiss M, et al. Infected mediastinal bronchogenic cyst successfuly treated by endobronchial ultrasound-guided fine-needle aspiration. Ann Thorac Surg 2010; 90: 52-3.

11. Fiorelli A, Rambaldi P, Accardo M, Santini M. Malignant transformation of bronchogenic cyst revealed by 99mTc-MIBI-SPECT. Asian Cardiovasc Thorac Ann 2012; 20: 347-9.

12. Aydoğdu K, Findik G, Ağackiran Y, Sahin F, Karaoğlanoğlu N, Taştepe I, et al. Mediastinal cystic lesions; experience of 77 patients. J Clin Anal Med 2013; 4: 381-5.

13. Ribet ME, Copin MC, Gosselin BH. Bronchogenic cysts of the lung. Ann Thorac Surg 1996; 61: 1636-40.

14. Arslan E, Şanlı M, Uluşan A, Yılmaz M, Elbeyli L. Servikal mediastinoskopi: Mediastinal kist eksizyonunda alternatif bir yöntem. Turk Gogus Kalp Dama 2013; 21: 813-6.

15. Barbetakis N, Asteriou C, Kleontas A, Papadopoulou F, Tsilikas C. Video-assisted thoracoscopik resection of a bronchogenic esophageal cyst. J Minim Access Surg 2011; 7: 249-52.

16. Lesaffer J, Heremans B, De leyn P, Van Raemdonck D. Video-assisted mediastinoscopic resection of a large symptomatic bronchogenic cyst.Interact Cardiovasc Thorac Surg 2011; 12: 1071-3.

17. Melfi F, Fanucchi O, Davini F, Viti A, Lucchi M, Ambrogi MC, et al. Ten-year experience of mediastinal robotic surgery in a single referral centre. Eur J Cardiothorac Surg 2012; 41: 847-51.

18. Kavaklı K, Gürkök S, Sapmaz E, Karataş O, Gözübüyük A. Benign mediastinal lezyonlara robotik yaklaşım. Turk Gogus Kalp Dama 2016; 24: 319-24. 
19. Generali T, Garatti A, Gabliardotto P, Frigiola A. Right mesothelial pericardial cyst determining intractable atrial arrhythmias. Interact Cardiovasc Thorac Surg 2011; 12: $837-9$.

20. Abad C, Rey A, Feijoo J, Gonzales G, Martin-Suarez J. Pericardial cyst: surgical resection in two symptomatic cases. J Cardiovasc Surg (Torino) 1996; 37: 199-202.

21. Comoglio C, Sansone F, Delsedime L, Campanella A, Ceresa F, Rinaldi M. Mesothelial cyst of the pericardium, absent on earlier computed tomography. Tex Heart Inst J 2010; 37: 354-7.

22. Sasaki H, Yano M, Kiriyama M, Kaji M, Fukai I, Yamakawa Y, et al. Multicystic mesothelial cyst of the mediastinum: report of a case. Surg Today 2003;33:199-201.

23. Potsis T, Nikas D, Patsouras D, Siogas K. Pericardial cyst in an unusual location. Hellenic J Cardiol 2012; 53: 318-9.

24. Riechelmann H, Muehlfay G, Keck T, Mattfeldt T, Rettinger G. Total, subtotal, and partial surgical removal of cervicofacial lymphangiomas. Arch Otolaryngol Head Neck Surg 1999; 125: 643-8.

25. Kibar AE, Çakır BÇ, Tiryaki T, Peltek N, Yılmaz H, Atayurt H ve ark. Göğüs duvarında kistik higroma: nadir bir yerleşim yeri. Türk Pediatri Arşivi 2005; 40: 241 3.

26. Efthymiou CA, Thorpe JA. Thymic cyst presenting as tachy-brady syndrome. Eur J Cardiothorac Surg 2009; 35: 1108-10. 
Table 1: Demographic properties of patients by histological type

\begin{tabular}{|c|c|c|c|c|}
\hline Property & $\begin{array}{c}\mathbf{P C} \\
(n=21) \\
\end{array}$ & $\begin{array}{c}\text { BC } \\
(n=16)\end{array}$ & $\begin{array}{l}\mathrm{CH} \\
(\mathrm{n}=3) \\
\end{array}$ & $\begin{array}{c}\mathbf{T C} \\
(\mathrm{n}=1) \\
\end{array}$ \\
\hline Sex, F/M & $10 / 11$ & $10 / 6$ & $1 / 2$ & $1 / 0$ \\
\hline Age, years* & $47 \pm 1,5$ & 43 & 49 & 53 \\
\hline Symptoms & $\begin{array}{l}\text { Chest pain, } \\
\text { cough, } \\
\text { dyspnea }\end{array}$ & $\begin{array}{l}\text { cough, } \\
\text { dyspnea }\end{array}$ & $\begin{array}{l}\text { Chest pain, } \\
\text { dyspnea }\end{array}$ & $\begin{array}{l}\text { Chest } \\
\text { pain, } \\
\text { dyspnea }\end{array}$ \\
\hline Mediastinal localization & Middle & $\begin{array}{l}\text { Anterior } 2, \\
\text { middle } 9, \\
\text { posterior } 5\end{array}$ & middle & anterior \\
\hline Maximum cyst diameter, $\mathrm{cm}^{*}$ & $4.6 \pm 1.3$ & $3.9 \pm 1.7$ & $6.9 \pm 1.2$ & 4 \\
\hline Thoracic CT & 15 & 13 & 2 & 1 \\
\hline Thoracic MR & 6 & 3 & 1 & 1 \\
\hline Surgical technique & $\begin{array}{l}\text { thoracotomy } \\
17, \text { VATS } 4\end{array}$ & $\begin{array}{l}\text { thoracotom } \\
\text { y } 13 \text {, } \\
\text { VATS } 3\end{array}$ & $\begin{array}{l}\text { thoracotom } \\
\text { y } 3\end{array}$ & $\begin{array}{l}\text { sternotom } \\
\mathrm{y}\end{array}$ \\
\hline Resection width & $\mathrm{TE}$ & $\mathrm{TE}$ & $\mathrm{TE}$ & $\mathrm{TE}$ \\
\hline Postoperative complication & $\begin{array}{l}\text { Atelectasi } 2 \\
\text { wound inf. } 1 \text {, } \\
\text { Phrenic } \\
\text { nevre } \\
\text { paralysis } 1\end{array}$ & $\begin{array}{l}\text { atelectasis } \\
1, \\
\text { prolonged } \\
\text { air leakage } \\
1\end{array}$ & $\begin{array}{l}\text { minimal } \\
\text { hemorrhag } \\
\text { e } 1\end{array}$ & no \\
\hline $\begin{array}{l}\text { Postoperative duration of hospital stay, } \\
\text { days }\end{array}$ & $4.0 \pm 1.0$ & $4.1 \pm 1.0$ & $5.0 \pm 1.0$ & 5 \\
\hline $\begin{array}{l}\text { Postoperative follow-up duration, } \\
\text { months }\end{array}$ & $9.0 \pm 3.3$ & $12.9 \pm 3.5$ & $11 \pm 1.5$ & 17 \\
\hline
\end{tabular}

